\title{
OCCUPATIONAL SHARPS INJURY AMONG HEALTHCARE WORKERS IN HOSPITAL MELAKA 2013 - 2015: A CROSS SECTIONAL STUDY
}

\author{
Abdullah Aliff Abdul Wahab ${ }^{1}$, Faiz Daud ${ }^{1,2}$, Nabilah Othman ${ }^{3}$ and Farhana Adila Sahak ${ }^{4}$ \\ ${ }^{1}$ Department of Community Health, The National University of Malaysia (UKM), 56000, Kuala Lumpur, Malaysia. \\ ${ }^{2}$ Graduate School of Business, SEGi University, Kota Damansara, 47810, Petaling Jaya, Selangor, Malaysia. \\ ${ }^{3}$ Medical Department, Hospital Tuanku Ja'afar, 70300 Seremban, Negeri Sembilan, Malaysia. \\ ${ }^{4} J a l a n$ Gereja Health Clinic, Jalan Gereja, Bandar Hilir, 75000 Melaka, Malaysia.
}

Corresponding author: Faiz Daud

Email: drfaizdaud@gmail.com

\begin{abstract}
Sharps injury imposed a major threat towards safety and health among healthcare workers (HCWs). Many studies in Malaysia concentrated on prevalence of needle stick injury (NSI), however the prevalence of sharps injury among HCWs based on local guideline was still scarce in Malaysia. This information gap leads us to conduct this study. Our study aimed to determine the prevalence of sharps injury among HCWs in Hospital Melaka and to describe the factors among staff with sharps injury. This cross-sectional study was conducted in Hospital Melaka, Malaysia. 165 reported cases from 2013-2015 were reviewed and secondary data extracted. Data was analyzed using IBM SPSS version 20. Among reported sharps injury cases in this study, 65 (39.4\%) were male, while 100 (60.6\%) were female. The mean age was 27.41 (SD: 6.06). More than half of the reported sharps injury occurred among doctor, 113 (68.5\%) specifically House Officer; 89 (53.9\%) followed by paramedic, 26 (15.8\%) and others, 26 (15.8\%). Mostly occurred in ward, 114 (69.1\%). The device which accounted for most of sharps injury cases was hypodermic needle, 67 (40.6\%). Many of the sharps injury cases occurred while withdrawing needle from patient, 26 (15.9\%). Prevalence of sharps injury among HCWs in this study was $0.8 \%$ in year 2013,1.1\% in year 2014 and $0.5 \%$ in year 2015 . Nearly half from the total number of reported sharps injury cases among HCWs in Hospital Melaka were from Medical Department, 71 (43\%). Recommended measures include usage of Safety-engineered devices (SEDs) and emphasize on standard precaution.
\end{abstract}

Keywords: Sharps Injury, Needlestick Injuries, Healthcare Workers

\section{INTRODUCTION}

Sharps injury is an exposure event occurring when any sharps penetrate the skin ${ }^{1}$. The event may impose a major threat towards safety and health among healthcare workers (HCWs). Therefore, it is important to conduct surveillance as part of sharps injury prevention program ${ }^{2}$. On the one hand, Centre for Disease Control and Prevention (CDC) defines sharps as any object that can penetrate the skin including, but not limited to needles, scalpels, broken glass, broken capillary tubes, and exposed ends of dental wires while needle stick defined as penetrating stab wounds caused by needles ${ }^{1}$. On the other hand, National Institute for Occupational Safety and Health (NIOSH) defines needlestick injuries among HCWs as injuries that are caused by needles such as hypodermic needles, blood collection needles, intravenous (IV) stylets, and needles used to connect parts of IV delivery systems ${ }^{3}$. In Malaysia, sharps defined as all sharp's instruments/devices used in healthcare facilities ${ }^{2}$ while needlestick injuries (NSI) defined as injuries caused by suture needles or hollow-bore needles ${ }^{4}$ ${ }^{5}$. Hollow-bore needle is a needle (e.g. hypodermic needle, phlebotomy needle) with a lumen through which material (e.g. medication, blood) can flow ${ }^{1}$.

Even though preventable, sharps injury remained as insidious harm or hazard among HCWs. Globally, sharps injury causes morbidity and mortality while seriously affecting health expenditure with costly Post Exposure Prophylaxis medication ${ }^{6}$. Approximately 3 million out of 35 million HCWs worldwide were exposed to blood borne pathogens each year due to sharps injury; two million of those exposed to HBV, 0.9 million to HCV and 170,000 to HIV. These injuries may have resulted in 70,000 HBV, $15,000 \mathrm{HCV}$ and 1,000 HIV infections ${ }^{7}$.

In Malaysia, the incidence of NSI in 2005 has been reported by the Occupational Health Unit in Ministry of Health at a rate of 4.7 per $1000 \mathrm{HCWs}^{8}$. Few studies in hospitals in Malaysia have shown prevalence of NSI of $24.6 \%, 23.5 \%, 20.9 \%$ and $9.8 \%$ in year 2003, 2008, 2013 and 2015 respectively ${ }^{9-12}$. Many studies in Malaysia have shown prevalence of NSI among HCWs, however the prevalence of sharps injury among HCWs which includes Ministry of Health staff, Ministry of Health trainees, Medical students and Health facilities support service workers according to Ministry of Health Malaysia Sharps Injury Surveillance Manual were still scarce in Malaysia ${ }^{2}$. This information gap leads us to conduct this study.

Our main objective is to determine prevalence of sharps injury among HCWs in Hospital Melaka based on the definition of HCWs in local Malaysian guidelines ${ }^{2}$ and to describe the factors among staff 
with sharps injury. In doing so, we hope to provide a better understanding of the reported sharps injury cases among HCWs in Hospital Melaka so that duly control measure could be taken.

\section{METHODOLOGY}

This cross-sectional study was conducted from 1st June 2016 until 31st July 2016 in Hospital Melaka; a full secondary care services provided by the Malaysian public facilities ${ }^{13}$.

\section{Population}

Registered cases of sharps injury in Melaka State Health Department's Registry of Sharps Injury Surveillance for the period of three years; from 1st January 2013 until 31st December 2015.

\section{Sampling and Sample}

We performed purposive sampling on Sharps Injury Surveillance Registry at the state level. From the total of 205 registered cases of sharps injury in Melaka State Health Department's Registry of Sharps Injury Surveillance during the three years study period,167 registered cases from Hospital Melaka were extracted. Out of these, two nonHCWs cases were excluded. Hence, only 165 cases which met the inclusion criteria for this study were selected for further analysis. Our inclusion criteria were reported and registered clinical HCWs in Hospital Melaka, Malaysia. Incomplete OHU/SIS-1 notification forms were excluded from this study.

\section{Data Collection}

A secondary source of data from Sharps Injury Surveillance Occupational Health Unit OHU/SIS-1 notification forms were used in this study.

\section{Data Analysis}

Data analysis was performed using IBM SPSS version 20. Descriptive analysis was done. Continuous variables were described with mean and standard deviation while categorical variables were described with frequency and percentage.

\section{Definition}

Our operational definition for HCWs in this study were Ministry of Health staff, Ministry of Health trainees, Medical students and Health facilities support service workers. On the one hand, clinical HCWs were those whom involved in direct patient care as part of their regular routine. On the other hand, nonclinical HCWs were those whom during their regular work routine were not involved in patient care or contact ${ }^{14}$. In our study, registered clinical HCWs were defined as HCWs involved in direct patient care and services (cleansing, linen, laundry, and healthcare waste management) as part of their regular routine whom registered under Human Resource Unit in Hospital Melaka.

\section{RESULT}

\section{Sociodemographic}

Among these reported cases, 65 (39.4\%) were male and 100 (60.6\%) were female. In 131 (79.4\%) cases, age were less than 30 years old while 34 (20.6\%) were 30 years old and above (Table 1 ). The mean age was 27.41 (SD: 6.06) and mostly occurred at age of 25 years. Majority 112 (67.9\%) had less than 25 months' experience in handling sharps.

In job category, Doctor; 113 (68.5\%) shows the highest number of sharps injury followed by Paramedic; 26 (15.8\%) and others; 26 (15.8\%). These occupations were House Officer; 89 (53.9\%) which remarkably shown the highest proportion among sharp-injured HCWs followed by senior doctors, MO; 20 (12.1\%) and nursing category (Matron / Sister / Staff Nurse / Assistant Nurse / Midwife / Community Nurse); 18 (10.9\%) (Table 1).

Majority 112 (67.9\%) had less than 25 months of experience in handling sharps while $53(32.1 \%)$ had 25 months and above of experience in handling sharps (Table 1). The mean experience was 31.02 (SD: 52.87) and most of sharps injury cases occurred at 2 months of experience in handling sharps.

\section{SD: standard deviations}

MO: Medical Officer 
Percentage of sharps injury according to occupation, $\mathrm{n}(165)$

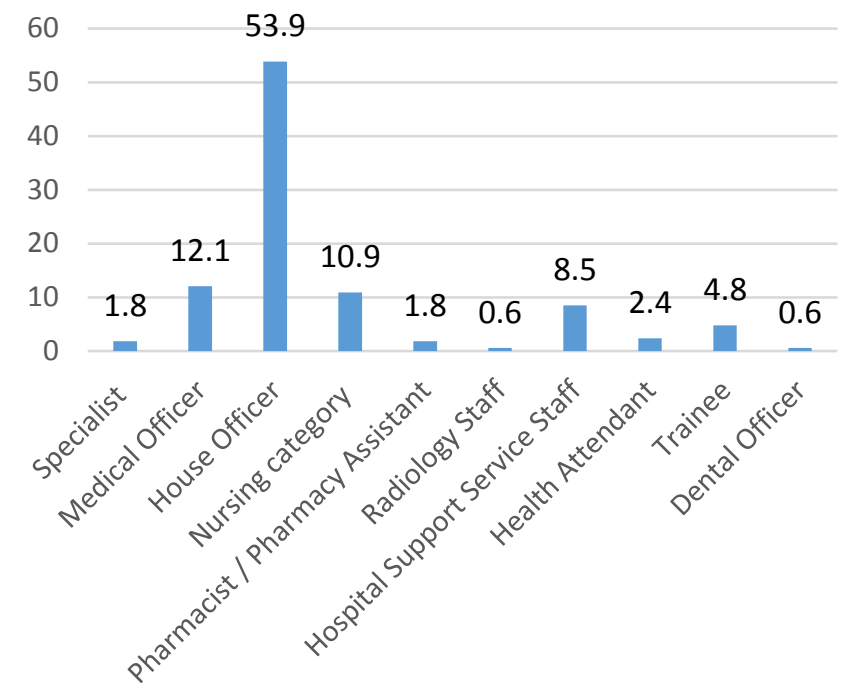

Figure 1: Percentage of sharps injury according to occupation

\section{Workplace}

Nearly half of the total number of reported sharps injury cases among HCWs in Hospital Melaka were from Medical Department, 71 (43\%) followed by Orthopedics Department, $22 \quad(13.3 \%)$ and Emergency \& Traumatology Department, 15 (9.1\%) (Table 3). In our study, most of sharps injury occurred in the ward, $114(69.1 \%)$. This was followed by operating theatre, $17(10.3 \%)$ and accident \& emergency, 14 (8.5\%) (Table 3). In the ward, sharps injury commonly occurred at patient's bedside $81 \quad(71.1 \%)$ while $29 \quad(25.4 \%)$ occurred elsewhere in ward and 4 (3.5\%) occurred by side room/nurses table (Table 3 ).

\section{Sharps devices (Hazard)}

The needle accounted for most of sharps injury cases, $130(78.8 \%)$ while surgical instruments or other items accounted for $35(21.2 \%)$ of sharps injury cases (Table 3 ). To be more precise, the top 3 devices which accounted for most of sharps injury cases were hypodermic needle, 67 (40.6\%), IV catheter stylet, $42(25.5 \%)$ and suture needle, 15 (9.1\%) (Table 3).

\section{Work process / causes}

Among the sharp-injured HCWs, many of these events occurred while doing work process of handling patient or needle/sharps, $75(45.7 \%)$ and handling equipment / specimens, $29(17.7 \%)$ or caused by sharps in unusual locations, $22(13.4 \%)$ (Table 3). Specifically, while withdrawing needle from patient, $26(15.9 \%)$ followed by passing / transferring equipment (needle / sharps), 24 $(14.6 \%)$ and suturing, 12 (7.3\%) (Table 4$)$.

Percentage of sharps injury according to work process/cause category, $\mathrm{n}(165)$

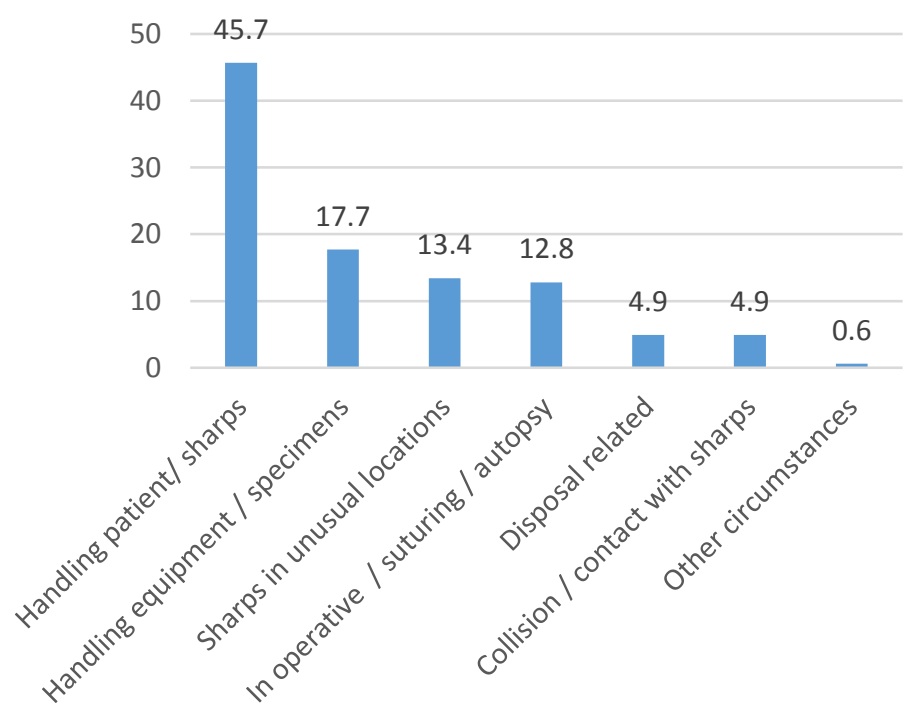

Figure 2: Percentage of sharps injury according to work process/cause category 


\section{Procedure}

Procedure that can be considered to be at greater risk of sharps injury among reported cases were drawing venous blood sample, 35 (21.2\%) and starting IV or setting up Heparin block (IV catheter or butterfly type needle), 28 (17\%) (Table 4).

\section{Exposure / contamination}

Most of the reported sharps injury cases were contaminated; known exposure to patient or contaminated equipment, $135(81.8 \%)$ while 26 (15.8\%) were unknown and 4 (2.4\%) were uncontaminated; no known exposure to patient or contaminated equipment (Table 4).

\section{Time category / shift}

Sharps injury mostly was reported to occur during the morning shift, $89(54.3 \%)$ as compared to evening shift, 60 (36.6\%) and night shift, 15 (9.1\%) (Table 3).

\section{Distribution of sharps injury by year}

This cross-sectional study was done on 3 years' secondary data of reported cases; 2013-2015. In year 2013, the reported cases of sharps injury were 58 (35.2\%) then in 2014, 73 (44.2\%) followed by 2015, 34 (20.6\%) (Table 1).

Table 1: Demographic details and year

\begin{tabular}{llll}
\hline Variables & Description & Frequency(n) & Percentage(\%) \\
\hline Gender & Female & 100 & 60.6 \\
\multirow{5}{*}{ Age } & Male & 65 & 39.4 \\
& Less than 30 years old & 131 & 79.4 \\
Job Category & Doctor & 34 & 20.6 \\
& Paramedic & & \\
& Others & 113 & 68.5 \\
\cline { 2 - 3 } Occupation old and above & 26 & 15.8 \\
& & 26 & 15.8 \\
& House Officer & & \\
& Medical Officer & 89 & 53.9 \\
& Nursing category & 20 & 12.1 \\
& Hospital Support Service Staff & 18 & 10.9 \\
& Trainee & 14 & 8.5 \\
& Medical Assistant & 8 & 4.8 \\
& Health Attendant & 4 & 2.4 \\
& Specialist / Consultant & 4 & 2.4 \\
& Pharmacist / Pharmacy Assistant & 3 & 1.8 \\
& Radiology Staff & 3 & 1.8 \\
& Dental Officer & 1 & 0.6 \\
& & 1 & 0.6 \\
Experience & Less than 25 months & 112 & 67.9 \\
& 25 months and above & 53 & 32.1 \\
& & & 35.2 \\
& 2013 & 73 & 44.2 \\
& 2014 & 34 & 20.6 \\
\hline
\end{tabular}

Table 2: Distribution of top 3 devices among top 5 workplace/department with reported sharps injury

\begin{tabular}{llll}
\hline Workplace & \multicolumn{3}{c}{ Device } \\
\cline { 2 - 3 } & $\begin{array}{l}\text { Hypodermic } \\
\text { needle }\end{array}$ & $\begin{array}{l}\text { IV catheter stylet } \\
\text { (venofix / branula) }\end{array}$ & Suture needle \\
\hline Medical & $38(62.3 \%)$ & $22(36.1 \%)$ & $1(1.6 \%)$ \\
Orthopedic & $6(50.0 \%)$ & $1(8.3 \%)$ & $5(41.7 \%)$ \\
Emergency \& traumatology & $6(50.0 \%)$ & $4(33.3 \%)$ & $2(16.7 \%)$ \\
Obstetrics \& gynecology & $4(30.8 \%)$ & $4(30.8 \%)$ & $5(38.4 \%)$ \\
Pediatric & $4(36.4 \%)$ & $7(63.6 \%)$ & $0(0.0 \%)$ \\
\hline
\end{tabular}

$\%$ within workplace category 
Prevalence of sharps injury in year 2013, 2014 and 2015

The number HCWs whom registered under Human Resource Unit in Hospital Melaka were as follows, 2013: 6928 HCWs, 2014: 6351 HCWs and 2015: 6646 HCWs. Based on the number of reported sharps injury cases as mentioned above, we manage to calculate the prevalence of sharps injury among HCWs in Hospital Melaka in year 2013, 2014 and 2015 as $0.8 \%, 1.1 \%$ and $0.5 \%$ respectively.

\section{Cross tabulation}

Distribution of top 3 devices and top 5 department with reported sharps injury

Among these top 3 devices, hypodermic needles, $38(62.3 \%)$ and IV catheter stylet (venofix/branula), $22(36.1 \%)$ commonly occurred in Medical Department. Suture needle mostly occurred in Orthopedic and Obstetrics \& Gynecology Department, $5(41.7 \%), 5(38.5 \%)$ respectively (Table 2).

\section{DISCUSSION}

Our main objective is to determine prevalence of sharps injury among HCWs in Hospital Melaka based on the definition of HCWs in local Malaysian guideline 2 and to describe the factors among staff with sharps injury. In doing so, we hope to provide a better understanding in the occurrence of sharps injury so that duly control measures could be taken. According to Part VIII, Section 32, Occupational Safety and Health Act 1994, an employer shall notify the nearest occupational safety and health office of any accident which has occurred at the place of work15. Therefore, our study which was focusing on reported cases represent the prevalence of sharps injury among HCWs in Hospital Melaka within the study period.

Based on the secondary data that had been collected, the prevalence of sharps injury among HCWs in this study was $0.8 \%$ in year $2013,1.1 \%$ in year 2014 and $0.5 \%$ in year 2015. These were lower than other studies in Malaysia which have shown prevalence of NSI of $24.6 \%, 23.5 \%, 20.9 \%$, and $9.8 \%$ in year 2003, 2008, 2013 and 2015 respectively9-12. The most plausible explanation for this is because in this study, we calculate the prevalence based on the definition of HCWs by local Malaysian guideline2 that includes vast variety of occupation serves under the Ministry of Health which were Ministry of Health Staff, Ministry of Health trainees, Medical students and Health facilities support service workers.

Among these reported cases, the mean age was 27.41 years (SD: 6.06) while the mean experience was 31.02 months (SD: 52.87). Most of the HCWs who reported to sustain sharps injury have experience less than 25 months in handling sharps. This is most probably due to the fact that most of the sharps injury cases were contributed by House Officer. On the one hand, another study founds the prevalence of NSI highest among those with less than 1-year work experience16. On the other hand, other study founds that those with work experience of 5 years and longer were significantly less likely to be injured ${ }^{17}$.

Several studies show that nurses have the highest proportion of NSI among HCWs; $27.9 \% 10,56.7 \%{ }^{16}$ and $62.3 \%{ }^{17}$. However, in our study, House Officer; 89 (53.9\%) shows the highest proportion of sharps injury among sharp-injured HCWs followed by senior doctors, MO; 20 (12.1\%) and nursing category (Matron / Sister / Staff Nurse / Assistant Nurse / Midwife / Community Nurse); 18 (10.9\%). This finding was similar to other study where the highest proportion of NSI was among doctors followed by nurses ${ }^{9,18}$.

Doctors especially House Officer were at risk of getting sharps injury in workplace. Most of them have less than 25-month experience in handling sharps. Hence, we assumed that those with less experience also lack in skill in handling sharps, particularly in this group of HCWs. Therefore, orientation regarding standard precaution ${ }^{19}$ and training should be emphasized among this group of HCWs.

Nearly half from the total number of reported sharps injury among HCWs in Hospital Melaka were from Medical Department, 71 (43\%). This finding was similar with study by Rampal et al in which majority, $51.9 \%$ of HCWs experienced needle stick and sharps injury in medical ward10. In our study, most of sharps injury occurred in ward, $114(69.1 \%)$, specifically occurred at patient's bedside 81 (71.1\%). Similarly, other study also found that majority of NSI occurred in ward, $36.5 \%{ }^{17}$.

Since the Medical Department has the highest number of wards/beds in comparison to other departments in Hospital Melaka; 14 wards out of 39 wards (35.9\%) while having 376 beds from the total 1074 beds (35\%), hence, we assumed that, with the greater number of wards/beds, the higher the likelihood thus the higher risk for HCWs in getting sharps injury20. This was most probably because the

Risk $=$ Likelihood $x$ Severity ${ }^{20}$ 
Table 3: Distribution of workplace, work unit, workstation, sharps category, work process and work shift

IV: Intravenous

\begin{tabular}{|c|c|c|c|}
\hline Variables & Description & Frequency(n) & Percentage(\%) \\
\hline Workplace / & Medical & 71 & 43.0 \\
\hline \multirow[t]{13}{*}{ Department } & Orthopedic & 22 & 13.3 \\
\hline & Emergency \& Traumatology & 15 & 9.1 \\
\hline & Obstetrics \& Gynecology & 14 & 8.5 \\
\hline & Pediatric & 12 & 7.3 \\
\hline & Surgery & 8 & 4.8 \\
\hline & Anesthesiology & 5 & 3.0 \\
\hline & Operation Theatre & 5 & 3.0 \\
\hline & Pharmacy & 3 & 1.8 \\
\hline & Dental & 3 & 1.8 \\
\hline & Radiology & 2 & 1.2 \\
\hline & Otorhinolaryngology & 2 & 1.2 \\
\hline & Pathology & 2 & 1.2 \\
\hline & Forensic & 1 & 0.6 \\
\hline \multirow[t]{8}{*}{ Work unit } & Ward & 114 & 69.1 \\
\hline & Operating Theatre & 17 & 10.3 \\
\hline & Accident \& Emergency & 14 & 8.5 \\
\hline & Others & 13 & 7.9 \\
\hline & Intensive Care Unit & 3 & 1.8 \\
\hline & Specialist Clinic & 1 & 0.6 \\
\hline & Dental Clinic & 2 & 1.2 \\
\hline & Laboratory & 1 & 0.6 \\
\hline \multirow{3}{*}{$\begin{array}{l}\text { Workstation } \\
\text { (ward) }\end{array}$} & At patient's bedside & 81 & 71.1 \\
\hline & Elsewhere in the ward & 29 & 25.4 \\
\hline & Side room / nurses table & 4 & 3.5 \\
\hline \multirow[t]{3}{*}{ Sharps category } & Needles & 130 & 78.8 \\
\hline & Surgical Instruments or Other Items & 35 & 21.2 \\
\hline & Glass & 0 & 0 \\
\hline \multirow[t]{12}{*}{ Specific devices } & Hypodermic needle & 67 & 40.6 \\
\hline & IV Catheter stylet (Venofix / Branula) & 42 & 25.5 \\
\hline & Suture Needle & 15 & 9.1 \\
\hline & Needle on IV line & 10 & 6.1 \\
\hline & Others (Sharps) & 10 & 6.1 \\
\hline & Others (Needles) & 6 & 3.6 \\
\hline & Scalpel & 5 & 3.0 \\
\hline & Wire (suture / fixation / guide wire) & 3 & 1.8 \\
\hline & Central line catheter introducer needle & 2 & 1.2 \\
\hline & Bone marrow needle & 2 & 1.2 \\
\hline & Razor & 2 & 1.2 \\
\hline & Biopsy needle & 1 & 0.6 \\
\hline \multirow{7}{*}{$\begin{array}{l}\text { Work process / cause } \\
\text { (category) }\end{array}$} & While handling patient or needle / sharps & 75 & 45.7 \\
\hline & Handling equipment / specimens & 29 & 17.7 \\
\hline & Sharps in unusual locations & 22 & 13.4 \\
\hline & While in operative field / suturing / autopsy & 21 & 12.8 \\
\hline & Collision / contact with sharps object & 8 & 4.9 \\
\hline & Disposal related & 8 & 4.9 \\
\hline & Other circumstances & 1 & 0.6 \\
\hline Time category / & Morning Shift & 89 & 54.3 \\
\hline \multirow{2}{*}{ work shift } & Evening Shift & 60 & 36.6 \\
\hline & Night Shift & 15 & 9.1 \\
\hline
\end{tabular}


Table 4: Distribution of work process (specific), procedure and exposure IV: Intravenous

\begin{tabular}{|c|c|c|c|}
\hline Variables & Description & Frequency(n) & Percentage(\%) \\
\hline Work process & While withdrawing needle from patient & 26 & 15.9 \\
\hline / causes & Passing / Transferring equipment & 24 & 14.6 \\
\hline \multirow[t]{30}{*}{ (specific) } & Suturing & 12 & 7.3 \\
\hline & While inserting needle in patient & 9 & 5.5 \\
\hline & During clean-up & 8 & 4.9 \\
\hline & While withdrawing needle from line & 7 & 4.3 \\
\hline & While manipulating needle in patient & 6 & 3.7 \\
\hline & In transit to disposal & 6 & 3.7 \\
\hline & Collided with sharps instrument & 6 & 3.7 \\
\hline & Left on table / tray & 6 & 3.7 \\
\hline & Other unusual locations & 5 & 3.0 \\
\hline & Incising & 4 & 2.4 \\
\hline & Handling equipment on tray / stand & 4 & 2.4 \\
\hline & Transferring blood / body fluids into specimen & 4 & 2.4 \\
\hline & container & 4 & 2.4 \\
\hline & Injured by sharps being disposed & 4 & 2.4 \\
\hline & In trash & 4 & 2.4 \\
\hline & On floor & 3 & 1.8 \\
\hline & Passing / receiving equipment & 3 & 1.8 \\
\hline & Disassembling device / equipment & 3 & 1.8 \\
\hline & While transporting the sharps to collection center & 3 & 1.8 \\
\hline & Left in bed / mattress & 2 & 1.2 \\
\hline & While manipulating needle in line & 2 & 1.2 \\
\hline & Palpating / Exploring & 2 & 1.2 \\
\hline & Sharps instrument dropped & 1 & 0.6 \\
\hline & While inserting needle in line & 1 & 0.6 \\
\hline & Manipulating suture needle in holder & 1 & 0.6 \\
\hline & Passing / tranferring equipment & 1 & 0.6 \\
\hline & Decontamination / processing of used equipment & 1 & 0.6 \\
\hline & While manipulating sharps bin & 1 & 0.6 \\
\hline & In linen / laundry & 1 & 0.6 \\
\hline & Other circumstances & & \\
\hline \multirow[t]{15}{*}{ Procedure } & Drawing venous blood sample & 35 & 21.2 \\
\hline & Starting IV or setting up Heparin block & 28 & 17.0 \\
\hline & Others & 20 & 12.1 \\
\hline & Injection & 19 & 11.5 \\
\hline & Suturing & 16 & 9.7 \\
\hline & Non medical procedures & 14 & 8.5 \\
\hline & Drawing arterial blood sample & 11 & 6.7 \\
\hline & Obtaining body fluid or tissue samples & 7 & 4.2 \\
\hline & Connecting IV line & 6 & 3.6 \\
\hline & Finger stick / Heel stik & 4 & 2.4 \\
\hline & Heparin or saline flush & 1 & 0.6 \\
\hline & Injections / aspiration at IV injection sites or IV ports & 1 & 0.6 \\
\hline & Placing an arterial / central line & 1 & 0.6 \\
\hline & Dissecting & 1 & 0.6 \\
\hline & Drilling & 1 & 0.6 \\
\hline Exposure/ & Contaminated & 135 & 81.8 \\
\hline \multirow[t]{2}{*}{ contamination } & Unknown & 26 & 15.8 \\
\hline & Uncontaminated & 4 & 2.4 \\
\hline
\end{tabular}

Among sharp devices, the device which considered most hazardous; accounted for most of sharps injury cases was hypodermic needle, 67 (40.6\%). This was also shown in other study done at hospital in Tehran ${ }^{16}$. Many of these events occurred while doing work process of withdrawing needle from patient, 26 (15.9\%) followed by passing / transferring equipment (needle / sharps), 24 $(14.6 \%)$ and suturing, 12 (7.3\%). In contrast with this finding, several studies ${ }^{9,10,17,21}$ shown that the work process which attributed most toward sharps injury were needle recapping, although National Institute for Occupational Safety and Health (NIOSH) had emphasized on avoiding needle recapping ${ }^{3}$. 
However, none of the sharps injury cases in our study were due to recapping of needles. Apart from that, Procedure with highest frequency of sharps injury among reported cases in our study was drawing venous blood sample, 35 (21.2\%). Similarly, this was shown by other studies ${ }^{9,22}$.

In our study, sharps injury cases mostly were reported to occur during the morning shift, 89 (54.3\%). Perhaps, this was due to the fact that most procedures were done after ward round in the morning shift. This finding was similar to study among nurses in hospital in Iran which reported nearly two thirds of NSI happened in the morning ${ }^{21}$.

Despites pre-existing control measures (written phlebotomy Standard operating procedures, poster, phlebotomy secretariat and training), the number of reported cases increased from year $2013(n=58)$ as compared to year 2014 ( $n=73), 25.9 \%$ increment. However, marked reduction of sharps injury was observed in year $2015(\mathrm{n}=34)$ as compared to year $2014(\mathrm{n}=73), 53.4 \%$ reduction.

This was most probably due to introduction of Safety-engineered devices (SEDs) in the hospital from years 2014 onwards. SEDs are sharp devices with an integrated safety feature designed to shield the needle or non-needle-sharp object after use $^{23-24}$. There was study regarding effectiveness of control measure by which access to devices with safety features was among the factors that decrease the frequency of $\mathrm{NSI}^{17}$. Another study pointed out that SEDs can reduce sharps injury rates with much reduction seen with safety cannula and blunt suture needles ${ }^{25}$.

\section{LIMITATION}

Since we gather mandatory self-reported secondary data, misclassification was possible such as recording error although every form/document had been reviewed by designated person in Public Health Unit in the hospital prior to notification in order to minimize this error.

\section{CONCLUSION}

By conducting this study, the prevalence of sharps injury among HCWs and factors among staff with sharps injury could be identified, thus provides a better understanding of the reported sharps injury cases among HCWs in Hospital Melaka so that duly control measure could be taken.

Standard precaution $^{19}$ and training should be emphasized among identified job category and department who at high risk of getting sharps injury. Other recommended measure includes usage of SEDs which most probably contributes to the reduction of sharps injury cases in year 2015.

However, we would recommend future study to measure the effectiveness of SEDs in reducing the number of sharps injury among HCWs.

\section{ACKNOWLEDGEMENT}

We would like to thank the Director General of Health Malaysia for his permission to publish this article (KKM/NIHSEC/800-4/4/1 Jld. 43 (07)). We also would like to thank Ministry of Health Malaysia and Hospital Melaka for consented us to conduct this study. This study receives funding from The National University of Malaysia (UKM) through GUP2017-061.

\section{REFERENCE}

1. Centre for Disease Control and Prevention (CDC). Workbook for Designing, Implementing, and Evaluating a Sharps Injury Prevention Program 2008:1-168.

2. Ministry of Health Malaysia. Sharps Injury Surveillance Manual (First Edition) 2007:1-46.

3. National Institute for Occupational Safety and Health (NIOSH). Preventing Needlestick Injuries in Health Care Settings [document on the Internet]. DHHS (NIOSH) Publication No. 2000108. 1999 [updated 6 June 2014; cited 1 July 2015]. Available from: https: //www.cdc.gov/niosh/docs/200 $0-108 / \mathrm{pdfs} / 2000$ -

108.pdf?id=10.26616/

NIOSHPUB2000108

4. Occupational Health Unit Ministry of Health Malaysia. Quality Assurance Manual: Number of Sharp Injuries Among Workers Within the Ministry of Health 2010:1-16.

5. Occupational Health Unit Ministry of Health Malaysia. Quality Assurance Indicator: Incidence Rate of Needlestick Injuries Among Health Care Workers Within the Ministry of Health 1998:1-6.

6. Mannocci A, De Carli G, Di Bari V et al. How Much do Needlestick Injuries Cost? A Systematic Review of the Economic Evaluations of Needlestick and Sharps Injuries among Healthcare Personnel. Infect Control Hosp Epidemiol 2016; 37(6):635-646.

7. Rapiti, E, Prüss-Üstün, A, Hutin, Y. Sharps injuries: Assessing the Burden of Disease from Sharps Injuries to Health Care Workers at National and Local Levels. World Health Organization Environmental Burden of Disease 2005; 11:1-50.

8. Occupational Health Unit Ministry of 
Health Malaysia. Guidelines on Occupational Exposures to Human Immunodeficiency Virus (HIV), Hepatitis B Virus (HBV) and Hepatitis C Virus (HCV), and Recommendations for Post Exposure Prophylaxis (PEP) 2009:1-30.

9. Lee LK, Noor Hassim I. Implication of the Prevalence of Needlestick Injuries in a General Hospital in Malaysia and Its Risk in Clinical Practice. Environ Health Prev Med 2005; 10:33-41.

10. Rampal L, Rosidah Z, Sook LW et al. Needle Stick and Sharps Injuries and Factors Associated Among Health Care Workers in a Malaysian Hospital. European Journal of Social Sciences 2010; 13(3):354-62.

11. Bhardwaj A, Sivapathasundaram N, Yusof MF et al. The Prevalence of Accidental Needle Stick Injury and Their Reporting Among Healthcare Workers in Orthopaedic Wards in General Hospital Melaka, Malaysia. Malaysian Orthopaedic Journal 2014; 8(2):6-13.

12. Nagandla K, Kumar K, Bhardwaj A et al. Prevalence of Needle Stick Injuries and Their Underreporting Among Healthcare Workers in The Department of Obstetrics and Gynaecology. Int Arch Med. 2015; 8(181):1-16.

13. Sarifah R. Chapter 3: Health Delivery System in Malaysia. [document on the Internet]. 2012. [cited 1 July 2015]. Available from: http://studentsrepo.um.edu.my/388 0/3/CHAP_3_-_CHAP_8.pdf

14. Seto WH, Cowling BJ, Lam HS et al. Clinical and Nonclinical Health Care Workers Faced a Similar Risk of Acquiring 2009 Pandemic H1N1 infection. Clin Infect Dis 2011; 53(3):280-283.

15. Law of Malaysia Act 514 Occupational Safety and Health Act 1994. [statute on the Internet]. 2015 [cited 1 July 2015]. Available from: http: / / www.dosh.gov.my/index.php/ en/list-of-documents/acts/23-02occupational safety-and-health-act1994-act-514/file

16. Yarahmadi R, Abbaszadeh Dizaji R, Hossieni AF et al. The Prevalence of Needle Sticks Injuries Among Health Care Workers at a Hospital in Tehran.
Iran J Health Saf Environ 2014; 1(1):23-9.

17. Hanafi MI, Mohamed AM, Kassem MS et al. Needlestick Injuries Among Health Care Workers of University of Alexandria Hospitals. East Mediterr Health J 2011; 17(1):26-35.

18. Amira CO, Awobusuyi JO. Needle-Stick Injury Among Health Care Workers in Hemodialysis Units in Nigeria: A MultiCenter Study. Int J Occup Environ Med 2014; 5(1):1-8.

19. Medical Development Division Ministry of Health Malaysia. Policies and Procedures on Infection Control $\left(2^{\text {nd }}\right.$ Edition) 2010:1-209.

20. Department of Occupational Safety and Health (DOSH), Ministry of Human Resources, Malaysia. Guidelines for Hazard Identification, Risk Assessment and Risk Control 2008:1-32.

21. Ebrahimi H, Khosravi A. Needlestick Injuries Among Nurses. J Res Health Sci 2007; 7(2):56-62.

22. Zafar A, Aslam N, Nasir $\mathrm{N}$ et al. Knowledge, Attitudes and Practices of Health Care Workers Regarding Needle Stick Injuries at a Tertiary Care Hospital in Pakistan. J Pak Med Assoc 2008; 58(2):57-60.

23. Tosini W, Ciotti C, Goyer F et al. Needlestick Injury Rates According to Different Types of Safety-Engineered Devices: Results of a French Multicenter Study. Infect Control Hosp Epidemiol 2010; 31(4):402-407.

24. Sohn S, Eagan J, Sepkowitz KA et al. Effect of Implementing SafetyEngineered Devices on Percutaneous Injury Epidemiology. Infect Control Hosp Epidemiol 2004; 25(7): 536-542.

25. Elder A, Paterson C. Sharps Injuries in UK Health Care: A Review of Injury Rates, Viral Transmission and Potential Efficacy of Safety Devices. Occup Med (Lond) 2006; 56(8):566-574. 